\title{
Genetic Polymorphism of the Glutathione S-transferase M1 and T1 Genes in Baghdad Population
}

\author{
Farha A.A. Shafi ${ }^{1} P h D$, Ban A. Abdul Majeed ${ }^{2} P h D$, Nada A. Al-Ansari ${ }^{3} P h D$ \\ ${ }^{1}$ Dept. of Biology, College of Science, Al-Mustansiriyah University, Baghdad, Iraq, ${ }^{2}$ Dept. of Pathology, College of \\ Medicine AL-Nahrain University, Baghdad, Iraq, ${ }^{3}$ Dept. of Biology, College of Science for Women, Baghdad University, \\ Baghdad, Iraq
}

\begin{abstract}
Background Glutathione S-transferases (GSTs) are enzymes of Phase II, which play an important role in cellular detoxification by conjugation of reduced glutathione with a wide variety of potentially toxic and carcinogenic. Polymorphisms of genes coding for the glutathione S-transferase (GST) enzymes were known to be associated with susceptibility to various forms of cancer, or outcome of multichemotherapeutic regimens.

Objective To analyze of the frequencies of the major polymorphisms of the GSTM1 and GSTT1 in Baghdad population to provide a basic database for future genetic and clinical studies.

Methods Peripheral blood was obtained from 142 healthy individuals randomly selected from two districts in Baghdad. The age of studied participants ranges from 15-46 yeares at time of inclusion. Genomic DNA was isolated from leukocytes using Wizerd genomic DNA purification kit. The GSTT1 and GSTM1 gene polymorphism were evaluated using multiplex polymerease chain reaction in which albumen gene was used as internal controls.

Results Twenty nine individuals (20.4\%) revealed no amplification of the GSTT1 gene (null type). The null GSTM1 genotype was found in $66.2 \%$ (94 individuals). Twelve percent (17/142) had null genotype for both genes. The most frequently observed genotype was GSTT1 positive/GSTM1 null genotype (54.2\%) while the GSTT1 null/GSTM1 positive genotype observed in 12 individuals (8.5\%). GSTT1postive/GSTM1 positive genotype was found in 36 (25.4\%) of the sample study.

Conclusion Data of the present study showed that the frequency of GSTT1 and GSTM1null genotype of the sample study is in concordance with those documented for Caucasian, Asians, and Arabs population. This study provides information for frequency distribution of GSTT1and GSTM1 null genotypes in the Baghdad population and information about genetic difference between Iraqi individuals and other population that provide basis for future genetics and clinical studies.

Keywords glutathione S-transferase, polymorphisms
\end{abstract}

List of abbreviation: GSTs = glutathione S-transferases, PCR = polymerase chain reaction

\section{Introduction}

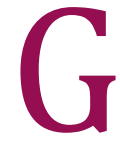
utathione represent a major superfamily of phase II drug-metabolizing enzymes that catalyze the conjugation of a large variety of endogenous and exogenous compounds, including environmental carcinogens and anticancer drugs and their metabolites with reduced glutathione ${ }^{(1)}$ and thereby protect cellular macrolecules against toxic foreign chemicals and oxidative stress

Moreover, GSTs are involved in the metabolism of isothiocyanates naturally occurring molecules that were recently shown to inhibit the development of tumors in many 
experimental models ${ }^{(2)}$. The GSTs include three major families of proteins: Cytosolic; mitochondrial and microsomal; the cytosolic GSTs constitute the largest family (1). In mammalian eight classes of cytosolic GSTs have been recognized: alpha (GSTA), mu (GSTM) theta (GSTT), pi (GSTP), zeta (GSTZ), sigma (GSTS), kappa (GSTK) and omega class (GSTO) $(3,4)$

Among the numerous GST genes, GSTM1 and GSTT1 genes have been extensively studied because of the high prevalence of homozygous deletions of these genes, which have been associated with the loss of enzyme activity with a decreased ability to detoxify and increase vulnerability to cytogenetic damage, placing null individuals at increase cancer risk ${ }^{(5-7)}$.

A mu class genes of GST family involve three alleles, two of them are active [GSTM1*A, GSTM $1 * B]$ and the third is a null allele [GSTM1*0]. GSTM1*0 allele is a deletion. Null phenotype (express no protein) produces by homozygotes for this allele (GSTM1 null genotype). GSTM1*A and GSTM1*B that differ by $C$ to $G$ substitution at base position 534 , and the catalytic effectiveness of the enzymes encoded by these alleles is similar ${ }^{(8)}$. GSTT1 is represented by two alleles: a functional or wild allele (GSTT1*1), and a nonfunctional or null allele $\left(\mathrm{GSTT} 1^{*} 0\right)$. Studies have shown that the total or partial deletion of the gene $($ GSTT $1 * 0$ allele) causing a deficiency in its enzymatic activity ${ }^{(9)}$.

The frequency of different polymorphic variants' varies with the ethnicity of a population; a number of studies from many countries on different geographic and racial groups have shown varied results on the incidence of null genotype frequency ${ }^{(10,11)}$. The frequencies of homozygous deletions of GSTT1 gene are higher in Asians and Africans than in Caucasians], whereas homozygous deletions of GSTM1 gene are higher in Caucasians and Asians than in Africans ${ }^{(12,13)}$.

Moreover, numerous studies have evaluated the association between polymorphisms of GSTs gene and the susceptibility to develop various types of cancer, such as gastric cancer, oral cancer, bladder cancer, and chronic myeloid leukemia $\mathrm{CML}$ in different ethnical groups worldwide ${ }^{(14-17)}$. Furthermore, other studies have found an association between GSTM1 and GSTT1 deletions and disease susceptibility, drug response and resistance to chemotherapy treatment ${ }^{(18-20)}$.

This study was done to analyze the frequencies of the major polymorphisms of GSTM1 and GSTT1 in a Baghdad population to provide basic information for future genetic and clinical studies.

\section{Methods}

The GSTT1 and GSTM1 gene polymorphism were evaluated using multiplex polymerase chain reaction (PCR) in which, albumen gene was used as internal controls. The PCR was carried out in mixture containing $5 \mu \mathrm{l}$ of genomic DNA, $25 \mu$ l of Go Taq green Master Mix (1X) and $2 \mu$ of each primer (20 PMol for each one) completed to $50 \mu \mathrm{l}$ with molecular grade water.

The sequences for the forward and reverse primers were 5-GAA CTC CCT GAA AAG CTA AAG C-3 and 5-GTT GGG CTC AAA TAT ACG GTG G-3 respectively for GSTM1. For the GSTT1, the primer sequences were F-5-TTC CTT ACT GGT CCT CAC ATC TC-3 and R-5-TCA CCG GAT CAT GGC CAG CA-3 respectively for GSTT1. Forward and reverse primers for albumin gene were 5GCC CTC TGC TAA CAA GTC CTA C-3 and 5-GCC CTA AAA AGA AAA TCG CCA ATC-3 respectively (21).

PCR amplification was performed with an initial denaturation at $94{ }^{\circ} \mathrm{C}$ for 3 minutes, followed by 35 cycles at $95{ }^{\circ} \mathrm{C}$ for 1 minute, $59^{\circ} \mathrm{C}$ for 1 minute, $72{ }^{\circ} \mathrm{C}$ for 1 minute and a last step was extension at $72^{\circ} \mathrm{C}$ for 5 minutes. PCR products were analyzed on a $2 \%$ agarose gel stained with $0.5 \mu \mathrm{g} / \mathrm{mL}$ ethidium bromide. The GSTT1, GSTM1 and albumin produce $480 \mathrm{bp}, 215 \mathrm{bp}$ and $350 \mathrm{bp}$ respectively. The presence of Albumin without GSTT1 or GSTM1 band on agarose gel reflects their deletion ${ }^{(21)}$. 


\section{Results}

\section{Genotyping analysis}

Genomic DNA was isolated from blood cells; all samples yielded intact genomic DNA. The GST genes (GSTT1, GSTM1) were successfully amplified in 142 samples (70 females and 72 males).

Gel electrophoresis of the amplified products revealed the presence of bands of GSTM1 gene at level of 215bp and GSTT1 gene at the level of $480 \mathrm{pb}$ bands. Null genotypes show absence of PCR product. In each reaction, coamplification of the albumin gene revealed a band with a product size of350bp (Figure 1).

The presence or absence of GSTM1 and GSTT1 genes was detected by the presence of a band at $215 \mathrm{bp}$ (corresponding to GSTM1) and a band at $480 \mathrm{bp}$ (corresponding to GSTT1). A band at $350 \mathrm{bp}$ (Corresponding to albumine gene) was always present and was used as an internal control to document successful PCR amplification. Lanes 1 , a negative control. Lane 2,8 individuals with null alleles for both GSTM1 and GSTT1 genes showing only one band at 350 bp corresponding to the internal control (albumine gene fragment). Lanes 3,4,5,9,10 individuals with GSTT1 present (480 bp) and GSTM1 null alleles. Lanes 6 and 7: individuals harboring GSTT1 null and GSTM1 present (215 bp) alleles. Lanes 11, 12 individuals with both GSTT1 and GSTM1 alleles present. $M$ is a DNA molecular marker (100bp).

Figure (2) summarize the frequency distribution of GSTT1 gene in the study sample. Postive amplification of GSTT1 was found in $113 / 142 \quad(79.6 \%)$ individuals. Twenty nine individuals (20.4\%) revealed no amplification of GSTT1 gene (null type).

The null GSTM1 genotype was found in $66.2 \%$ (94 individuals) as shown in (figure 3 ). The distribution and frequencies of the combined genotypes of GSTT1 andGSTM1We was examined (Figure 4), it revealed that the most frequently observed combinnant was GSTT1 positive /GSTM1 null genotype (54.2\%) while the GSTT1 null/GSTM1 postive genotye observed in 12 individuals (8.5\%). The GSTT1 positive/GSTM1 positive genotype was found in $25.4 \%$ (36) of the sample study and twelve percent (17/142) had null genotype for both genes.

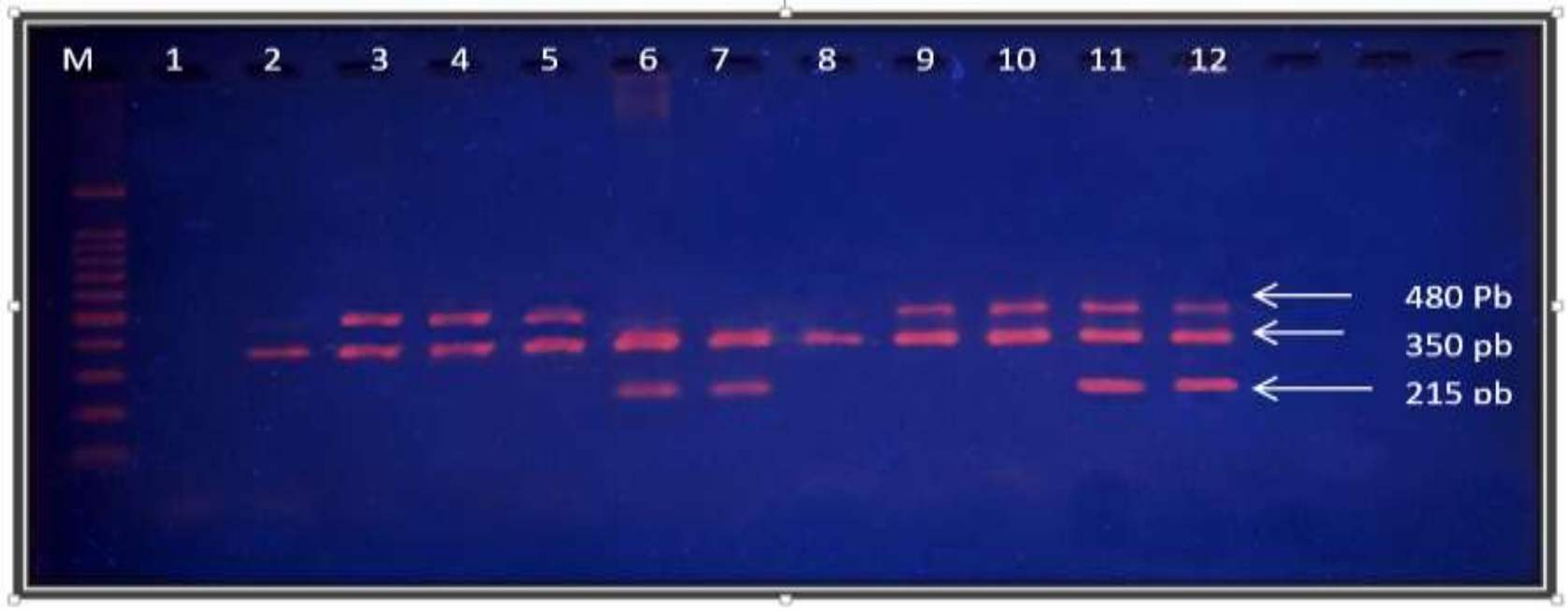

Fig. 1. Multiplex PCR products analyzed on 2\% agarose gel. The presence or absence of GSTM1 and GSTT1 genes was detected by the presence of a band at 215 bp (corresponding to GSTM1) and a band at 480 bp (corresponding to GSTT1). A band at $350 \mathrm{bp}$ (Corresponding to albumine gene) was always present and was used as an internal control to document successful PCR amplification. Lanes 1, a negative control. Lane 2,8 individuals with null alleles for both GSTM1 and GSTT1 genes showing only one band at 350 bp corresponding to the internal control (albumine gene fragment). Lanes 3,4,5,9,10 individuals with GSTT1 present (480 bp) and GSTM1 null alleles. Lanes 6 and 7: individuals harboring GSTT1 null and GSTM1 present (215 bp) alleles. Lanes 11, 12 individuals with both GSTT1 and GSTM1 alleles present. $M$ is a DNA molecular marker (100bp). 


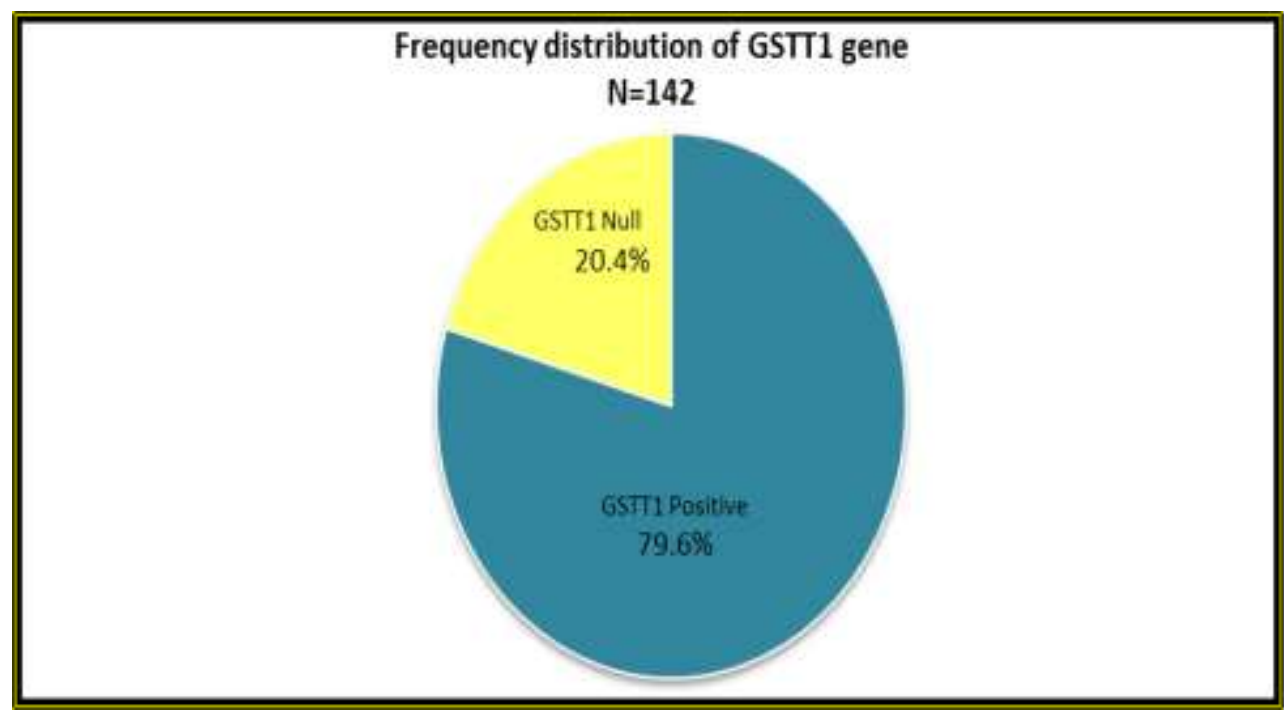

Fig. 2. Frequency distribution of GSTT1 gene in the total sample

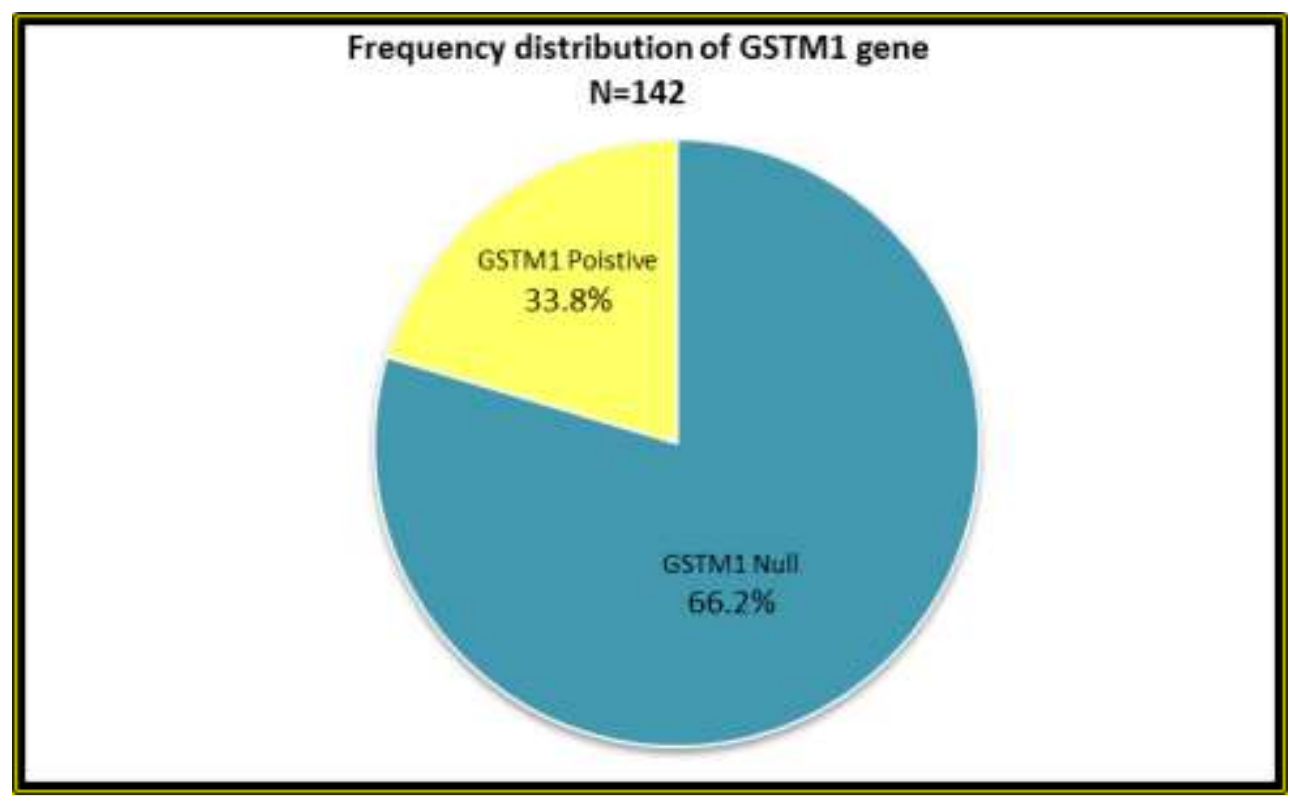

Fig. 3. Frequency distribution of GSTM1 gene in the total sample study 


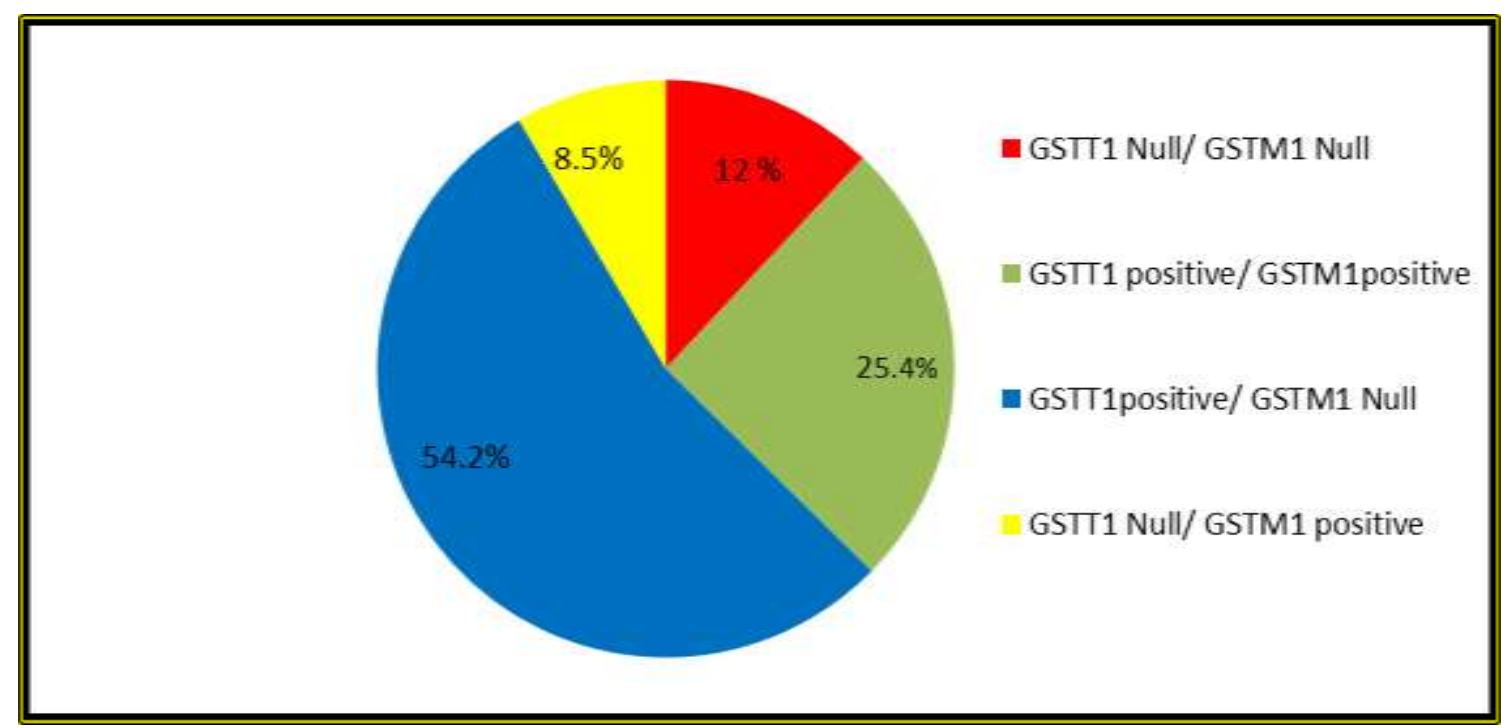

Fig. 4. The frequency distribution of four types of gene combination in the total sample $(n=142)$

\section{Discussion}

The present study revealed that the frequency of GSTT1 null genotype is (20.4\%), this frequency is higher than those reported in a previous case control study that was performed by Al-Awadiy et al ${ }^{(22)}$ in the Iraqi population, which was (6.9\%). The GSTT1 null genotype frequency was similar to Caucasian (19.7\%) and concordant with those documented for Turkish (23\%) population and was lower than that reported in Arab (37.1\%) and African (26\%) population ${ }^{(25,30)}$ (table 1 ).

The GSTM1 null genotype frequency (66.2\%) reported in the current study was comparable to that observed in Asians and Caucasians (40$62 \%)^{(23)}$ but higher than that observed in African (26.7\%) The proportion of double nulls (GSTM1 and GSTT1 null genotypes), synonymous of absence of enzyme activity in the sample study (12\%) was concordant to that previously reported by Al-Awadi et al (22) for the Iraqi population(10\%) as well as for other Arab populations, including Bahraini (14.4\%); Lebanese (16.3\%) population; and it is nearly similar to that of the Caucasians and African population and less than that observed in Arabs (Saudi) population ${ }^{(24,25)}$.

Worldwide variation in GSTT1 and GSTM1 frequency were previously reported. Abdel
Halim et al (24) demonstrated that the difference of GTSM1 and GSTT1 alleles' frequency among different population are attributed to their evolutionary histories, and to selection arising from varied exposures to toxic substances.

The (GST) genes are crucially involved in the detoxification of a variety of exogenous carcinogens and mutagens. Individuals with GSTM1 and GSTT1 null genotypes being less efficient at processing carcinogens and radicals oxygen species ${ }^{(7)}$.

The polymorphisms in both GSTT1 and GSTM1 genes were widely studied in relation to genotoxic damage in peripheral blood cells of the general population and of groups occupationally exposed to known or suspected genotoxic materials. Many studies focused on the possible association between the GSTT1 and GSTM1 polymorphisms and various diseases but the results are variables.Several studies have reported a relationship between combination of the GST genotype and risk of various diseases and some of them had suggested a possible synergistic effect between GST genotype ${ }^{(26,27)}$. 
Table 1. Comparison between the results of the present study with the frequency of GSTM1 and GSTT1 In the other regions of the world

\begin{tabular}{cccccc}
\hline Population & $\mathbf{n}$ & GSTM1 null \% & GSTT1 null\% & Double null\% & Reference \\
\hline Baghdad & 142 & 66.2 & 20.4 & 12 & Present study \\
Bahrainis & & 49.7 & 28.7 & 14.4 & \\
$\begin{array}{c}\text { Lebanese } \\
\text { Tunisians }\end{array}$ & 167 & 52.5 & 37.6 & 16.3 & 24 \\
Syria & 141 & 20.7 & 16.7 & 3.97 & 28 \\
Arabs & 172 & 54.6 & 25.9 & 17.2 & 25 \\
$\begin{array}{c}\text { (95\% Saudi) } \\
\text { Iranian }\end{array}$ & 513 & 63.4 & 37.1 & 21 & 29 \\
Turkish & 235 & 46 & 72 & 16 & 30 \\
Caucasian & 50 & 52 & 23 & NA & 25 \\
African & 486 & 53.1 & 19.7 & 10.4 & 25 \\
\hline
\end{tabular}

$\mathrm{n}=$ number of subjects, NA = data not available

In conclusion, this study provides information for GSTT1 and GSTM1 postive/null genotype in the Baghdad population this data will help the future clinical and genetic studies relating to the differences in the response or toxicity to xenobiotics or drugs known to be substrates of glutathione-S-transferases.

\section{Acknowledgments}

The authors would like to thank the Department of Biology, College of Science for Woman, University of Baghdad for their valuable technical support, and we are grateful to all individuals for kindly giving us the blood samples.

\section{Author contribution}

Research proposal was done by Dr. Nada and Prof. Dr. Ban. While collection of samples, individuals' interview and interpretation of results were done by Dr. Farha.

\section{Conflict of interest}

The author declared no conflict of interest for the present research outcome.

\section{Funding}

Authors depend on self-funding.

\section{References}

1. Hayes JD, Flanagan JU, Jowsey IR. Glutathione transferases. Annu Rev Pharmacol Toxicol. 2005; 45: 51-88.

2. Conaway $C$, Yang $M$, Chung L. Isothiocyanates as cancer chemopreventive agents: their biological activities and metabolism in rodents and humans. Curr Drug Metab. 2002; 3: 233-55.

3. Mannervik B, Awasthi Y, Board P, et al. Nomenclature for human glutathione transferases. Biochem J. 1992; 282: 305-6.

4. Mannervik B, Board P, Hayes D, et al. Nomenclature for mammalian soluble glutathione transferases. Methods Enzymol. 2005; 401: 1-8.

5. Bolufer $P$, Barragan $E$, Collado $M$, et al. Influence of genetic polymorphisms on the risk of developing leukemia and on disease progression. Leuk. Res. 2006; 30: 1471-91. 
6. Bolt HM, Thier R. Relevance of the deletion polymorphisms of the glutathione S-transferases GSTT1 and GSTM1 in pharmacology and toxicology. Curr Drug Metab. 2006; 7: 613-28.

7. Al-Sarraji FAA. Molecular and cytogenetic studies of human populations in two districts of Baghdad. PhD thesis, College of Science, Baghdad University, Baghdad, Iraq, 2013.

8. Seidegard J, Yorachek WR, Pero RW et al. Heredity differences in the expression of the human glutathione transferase active on trans-stilbene oxide are due to gene deletion. Proc Natl Acad Sci USA. 1988; 85: 7293-7.

9. Pemble $S$, Schroeder KR, Spencer SR, et al. Human glutathione S-transferase theta (GSTT1): cDNA cloning and the characterization of a genetic polymorphism. Biochem J. 1994; 300: 271-6.

10. Rossini A, Davy CM, Amorim LM, et al. Frequencies of GSTM1, GSTT1 and GSTP1 polymorphisms in a Brazilian population. Genet Mol Res.2002; 1: 233-40.

11. Chen C, Hsu L, Wang C, et al. Biomarker of exposure, effect, and susceptibility of arsinc-induced health hazards in Taiwan. Toxicol App Pharmacol. 2005; 206: 198-206.

12. Bailey LR, Roodi N, Verrier CS, et al. Breast cancer and CYP1A1, GSTM1, and GSTT1 polymorphism: evidence of a lack of association in Caucasians and African Americans. Cancer Res. 1998; 58: 65-70.

13. Roth MJ, Dawsey SM, Wang G, et al. Association between $\mathrm{GSTM} 1^{*} 0$ and squamous dysplasia of the esophagus in the high-risk region of Linxian, China. Cancer Lett. 2000; 156: 73-81.

14. Ma W, Zhuang $L$, Han B, et al. Association between glutathione S-transferase T1 null genotype and gastric cancer risk: a meta-analysis of 48 studies. PLoS One. 2013; 8(4): e60833.

15. Dong G, Tian $Y$, Chen $S$, et al. Glutathione Stransferase T1 null genotype is associated with oral cancer susceptibility in Asian populations. Tumor Biol. 2013; 34: 1753-7.

16. Berber $U$, Yilmaz I, Yilmaz $O$, et al. CYP1A1 (lle462Val), CYP1B1 (Ala119Ser and Val432Leu), GSTM1 (null), and GSTT1 (null) polymorphisms and bladder cancer risk in a Turkish population. Asian Pac J Cancer Prev. 2013; 14: 3925-9.

17. Kassogue $Y$, Dehbi $H$, Quachouh $M$, et al. Association of glutathione S-transferase (GSTM1 and GSTT1) genes with chronic myeloid leukemia. Springerplus. 2015; 4: 210. doi: 10.1186/s40064-015-0966-y

18. Takanashi $M$, Morimoto $A$, Yagi $T$, et al. Impact of glutathione S-transferase gene deletion on early relapse in childhood B-precursor acute lymphoblastic leukemia. Haematologica. 2003; 88, 1238-44.

19. Mehmet G, Selin U, Duygu $E$, et al. Role of glutathione S-transferase $\mathrm{M} 1, \mathrm{~T} 1$ and $\mathrm{P} 1$ gene polymorphisms in childhood acute lymphoblastic leukemia susceptibility in a Turkish population. Meta Gene. 2015; 5: 115-9.

20. Myles S, Tang $\mathrm{K}$, Somel $\mathrm{M}$, et al. Identification and analysis of genomic regions with large betweenpopulation differentiation in humans. Ann Hum Genet. 2008; 72: 99-110.

21. Arand $M$, Muhlbauer $R$, Hengstler J, et al. A multiplex polymerase chain reaction protocol for the simultaneous analysis of the glutathione $\mathrm{S}$ transferase GSTM1 and GSTT1 polymorphisms. Anal Biochem. 1996; 236: 184-6.

22. Al-Awadi SJ, Aziz IH, Al-Badran Al. Frequency of GSTM1 and GSTT1 polymorphisms in Iraqi population. J Basrah Res. (Sciences). 2009; 35: 26-32.

23. Garte S, Gaspari L, Alexandrie A. Metabolic gene polymorphism frequencies in control populations. Cancer Epidemiol Biomarkers Prev. 2001, 10: 123948.

24. Abdel Halim S, Alaeddin Y, Muhalab Al, et al. Genetic polymorphism of the glutathione S-transferase $\mathrm{M} 1$ and T1 genes in three distinct Arab populations Disease Markers. 2011; 31: 311-6.

25. Bu R, Gutiérrez MI, Al-Rasheed $M$, et al. Variable drug metabolism genes in Arab Population. The Pharmacogenomics J. 2004; 4: 260-6.

26. Sayaka K, Erich MS, Fanglin L, et al. GSTM1 and GSTT1 null polymorphisms and risk of salivary gland carcinoma. Int J Clin Exp Med. 2009; 2: 68-75.

27. Wang $\mathrm{Y}, \mathrm{He} J, \mathrm{Ma} \mathrm{T}$, et al. GSTT1 Null genotype significantly increases the susceptibility to urinary system cancer: evidences from 63,876 subjects. J Cancer. 2016; 7: 1680-98.

28. Al-Achkar W, Ghassan A, Moassass F, et al. Influence of CYP1A1, GST polymorphisms and susceptibility risk of chronic myeloid leukemia in Syrian population. Med Oncol. 2014; 31: 889. doi:10.1007/s12032-0140889-4.

29. Torkaman-Boutorabi A, Hoormand $M$, Naghdi N. Genotype and allele frequencies of $\mathrm{N}$ acetyltransferase 2 and glutathione S-transferase in the Iranian population. Clin Exp Pharmacol Physiol. 2007; 34: 1207-11.

30. Karaca S, Karaca MT, Cesuroglu S, et al. GSTM1, GSTP1, and GSTT1 genetic variability in Turkish and worldwide populations. Am J Hum Biol. 2015; 27: 310-6.

\footnotetext{
Correspondence to Farha A.A. Shafi E-mail: frahaali2009@yahoo.com Received 22 ${ }^{\text {nd }}$ Dec. 2015: Accepted $23^{\text {th }}$ May 2016
} 